\title{
Atlantoaxial instability and abnormalities of the odontoid in Down's syndrome
}

\author{
S ELLIOTT, ${ }^{*}$ R E MORTON, $\dagger$ AND R A J WHITELAW* $\ddagger$ \\ ${ }^{*}$ Department of Radiology, Derbyshire Royal Infirmary and Departments of $†$ Paediatrics and $\ddagger$ Radiology, \\ Derbyshire Children's Hospital, Derby
}

SUMMARY Radiography of the lateral neck was performed on all children with Down's syndrome aged $4-15$ in the Southern Derbyshire health district $(n=67)$ and a random selection of adults $(n=94)$. Atlantoaxial instability, defined as a gap of over $4 \mathrm{~mm}$, was present in seven $(10 \%)$ children and two $(2 \%)$ adults. Odontoid hypoplasia, defined as an odontoid peg two standard deviations below the mean in an age matched population, was present in $15(22 \%)$ children and $14(15 \%)$ adults, with accessory odontoid ossicles present in two (2\%) and two (3\%) respectively. No one was found to have symptoms or clinical signs of spinal cord compression. Atlantoaxial instability was therefore found to be commoner in children than adults. Different programmes of management are suggested, in terms of regular clinical examination for signs and symptoms and by radiographic screening. Particular care should be taken with those who have both atlantoaxial instability and odontoid hypoplasia or accessory ossicles as they are at particular risk of spinal cord damage.

Interest in upper cervical instability in Down's syndrome has recently been renewed after the recommendation by the Committee on Sports of the American Academy of Pediatrics relating to participation in sporting activities. ${ }^{1}$ The Committee recommends preparticipation radiographs of the cervical spine in flexion, extension, and neutral, with attention being directed to the atlantoaxial region in order to prevent serious damage to the spinal cord. Similar recommendations have been made in Britain by the Department of Health and Social Security (DHSS) ${ }^{2}$ and Mencap. ${ }^{3}$

Abnormalities of the upper cervical spine in Down's syndrome have been recognised since the original work of Tishler and Martel in $1965 .^{4}$ There is a reported incidence of atlantoaxial instability of between 9.5 and $27 \% .^{5-7}$ People with Down's syndrome also have an increased incidence of abnormalities of the odontoid peg $^{6}$ and this may predispose to damage if they also have atlantoaxial instability. ${ }^{8}$ We found 13 cases of symptomatic atlantoaxial instability in Down's syndrome reported in the literature in which features of the odontoid peg were specifically mentioned. All 13 had accessory ossicles and eight had coexistent odontoid hypoplasia, although the size of the odontoid peg was not mentioned in the other five. ${ }^{8-17}$
Unfortunately, surveys of atlantoaxial instability in Down's syndrome have generally been unable to comment on coexistent odontoid hypoplasia because of the lack of normative data for the growth of the odontoid peg during childhood. Some surveys have also reported atlanto-occipital instability which may lead to symptoms. ${ }^{12} 1819$ We report the only United Kingdom survey of radiographic screening in children and adults with Down's syndrome. Particular attention was paid to the presence of odontoid hypoplasia, using criteria for hypoplasia established in a parallel examination of cervical radiography in 500 normal children. ${ }^{20}$

\section{Subjects and methods}

Radiographs of the cervical spine were performed in all children in the Southern Derbyshire health district between the ages of 4 and $15(n=67)$ and a random number of adults with Down's syndrome $(n=94)$. The adults included 60 from adult training centres and 35 from the district long stay hospital. Radiographs were taken of the lateral cervical spine in flexion, extension, and neutral, at a film focus distance of $200 \mathrm{~cm}$, as described by Clark. ${ }^{21}$ All films were reviewed by two of the authors (SE and RAJW) and assessed for (1) atlantoaxial instability, (2) odontoid hypoplasia and accessory ossicles (os 
odontoideum and os terminale), and (3) atlantooccipital instability. One adult refused to have a radiograph taken and was excluded from the results.

(1) Atlantoaxial instability was assessed by measuring the distance between the posteriorinferior aspect of the anterior arch of the atlas and the nearest adjacent surface of the odontoid process ( $\mathrm{z}$, fig 1). Measurements over 4 $\mathrm{mm}$ were taken as abnormal. 22

(2) The hypoplastic odontoid has loosely been defined as an odontoid not reaching the upper edge of the anterior arch of the atlas. ${ }^{23}$ We have recently found, however, that this is often a normal finding in children up to the age of about $9 .{ }^{20}$ We assessed the height of the odontoid using the method described by McManners, measuring from the tip of the odontoid process to the superior aspect of the articular facets of $\mathrm{C} 2(\mathrm{y}$, fig 1$) .{ }^{24}$ In addition, we measured the distance from the tip of the odontoid process to the superior edge of the anterior arch of the atlas, which we termed the odontoid 'deficiency' ( $x$, fig 1). The latter measurement must be taken (from a lateral radiograph) in the neutral postion. ${ }^{23}$ Measurements of odontoid hypoplasia and deficiency were compared with measurements obtained in 500 age matched individuals up to the age of $20 .{ }^{20}$

(3) Atlanto-occipital instability was assessed by

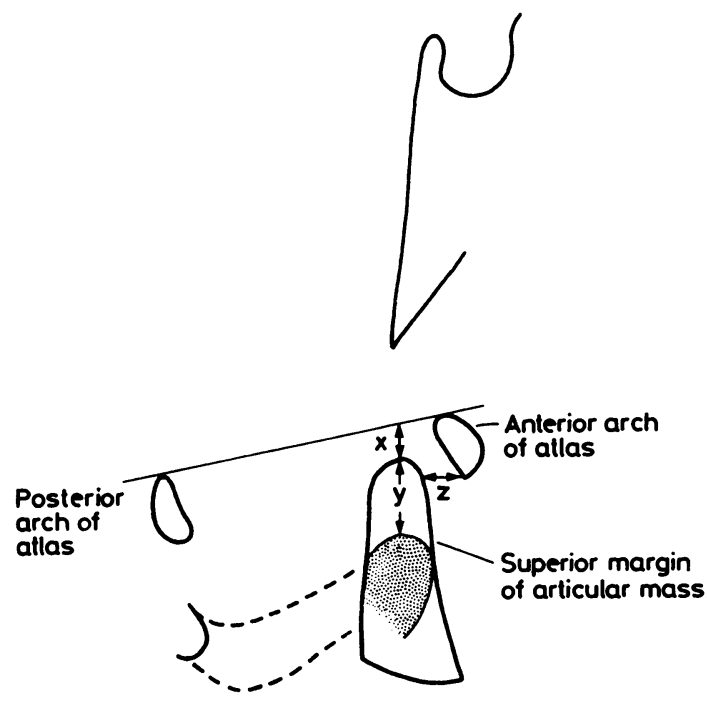

Fig 1 Parameters measured in assessment of the atlantoaxial region: $x=$ odontoid deficiency; $y=$ odontoid height; and $z=$ atlantoaxial gap. the method of El Khoury et al. ${ }^{19}$ In normal people, the odontoid lies directly beneath the basion and this does not change with neck movement. This is not the case, however, when atlantoaxial instability occurs and the atlantooccipital distance is better measured by the distance between the anterior arch of the atlas and the basion.

In this study we considered adults to be those over the age of 15 years. Growth of the odontoid peg may be delayed in Down's syndrome during childhood because of bony immaturity, however, and we assessed normal adult values from those over the age of 19 years: these were very similar to adult values in the series of McManners. ${ }^{24}$

All patients under the age of 15 were seen by a clinician (RM) who checked for signs and symptoms of spinal cord compression. Those over the age of 15 were only seen by a clinician if atlantoaxial instability was found on the radiograph.

Statistical analysis of the results was performed by the Student's $t$ test.

\section{Results}

Details of the atlantoaxial gap and the incidence of atlantoaxial instability in males and females above and below the age of 15 is given in table 1 . Atlantoaxial instability was present in no children out of 11 under the age of 5 , in five children out of $30(17 \%)$ between 5 and 9 , and two children out of $26(8 \%)$ between 10 and 14 years. The incidence of odontoid hypoplasia, odontoid deficiency, and accessory ossicles is given in table 2 .

Maximal atlantoaxial instability was always shown on the flexion film. In extension, the gap tended to decrease and the odontoid peg was not shown as well as on the neutral film. The size of the odontoid peg in our patients with Down's syndrome was

Table 1 Atlantoaxial gap and incidence of atlantoaxial instability in Down's syndrome

\begin{tabular}{|c|c|c|}
\hline & $\begin{array}{l}\text { Mean } \\
\text { atlantoaxial } \\
\text { gap (mm) (SD) }\end{array}$ & $\begin{array}{l}\text { No (\%) with } \\
\text { atlantoaxial } \\
\text { instability }\end{array}$ \\
\hline \multicolumn{3}{|c|}{$<15$ years } \\
\hline Male $\quad(n=28)$ & $2.9(1.3)$ & $4(14)$ \\
\hline Female $(n=39)$ & $2 \cdot 8(1 \cdot 2)$ & $3(8)$ \\
\hline Total $\quad(n=67)$ & $2 \cdot 9(1 \cdot 2)^{*}$ & $7(10)^{*}$ \\
\hline \multicolumn{3}{|c|}{$\geqslant 15$ years } \\
\hline Male $\quad(n=51)$ & $2 \cdot 1(1 \cdot 8)$ & $1(2)$ \\
\hline Female $(n=43)$ & $1.8(0.9)$ & $1(2)$ \\
\hline Total $\quad(n=94)$ & $1.9(1.5)^{*}$ & $2(2)^{*}$ \\
\hline
\end{tabular}

${ }^{*}$ Significant difference, $\mathrm{p}<0 \cdot 05$. 
compared with the peg size for the same age range in normals (shown in fig 2). Although there was a tendency for the peg to be generally smaller in Down's syndrome, this only achieved significance in the adult group.

Measurements of the odontoid deficiency in people with Down's syndrome was compared with normal controls (fig 3). Again, there was a tendency for a greater odontoid deficiency in Down's syndrome but this was only significant in the adults.

One child had appreciable atlantoaxial instability and odontoid hypoplasia. One adult had appreciable

Table 2 Problems of the odontoid peg in Down's syndrome

\begin{tabular}{lccl}
\hline & $\begin{array}{l}\text { No (\%) with } \\
\text { odontoid } \\
\text { hypoplasia }\end{array}$ & $\begin{array}{l}\text { No (\%) with } \\
\text { significant } \\
\text { deficiency }\end{array}$ & $\begin{array}{l}\text { No (\%) with } \\
\text { accessory } \\
\text { ossicles }\end{array}$ \\
\hline \multicolumn{5}{c}{$<19$ years } \\
Males $(\mathrm{n}=39)$ & $6(15)$ & $6(15)$ & $1(2)$ \\
Females $(\mathrm{n}=51)$ & $9(17)$ & $3(6)$ & $1(3)$ \\
Total $(\mathrm{n}=90)$ & $15(17)$ & $9(10)$ & $2(2)$ \\
Males $(\mathrm{n}=40)$ & $5(13)$ & $2(5)$ & $1(2)$ \\
Females $(\mathrm{n}=31)$ & $9(29)$ & $2(6)$ & $1(2)$ \\
Total $(\mathrm{n}=71)$ & $14(20)$ & $4(6)$ & $2(3)$ \\
\hline
\end{tabular}

There were no significant differences.

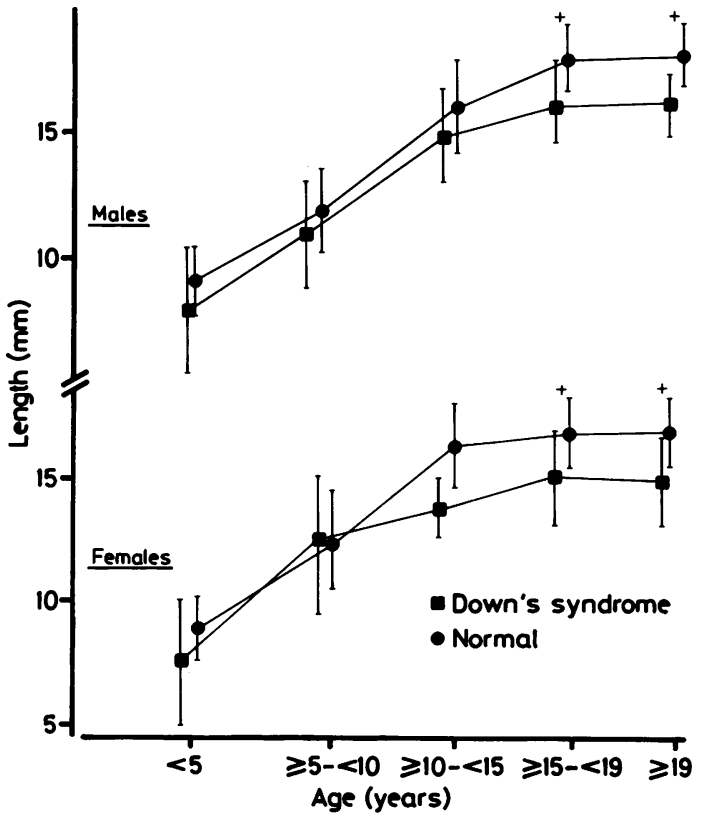

Fig 2 Length of odontoid peg at different ages in people with Down's syndrome and in normal controls. $+=$ Significant difference, $p<0 \cdot 05$.

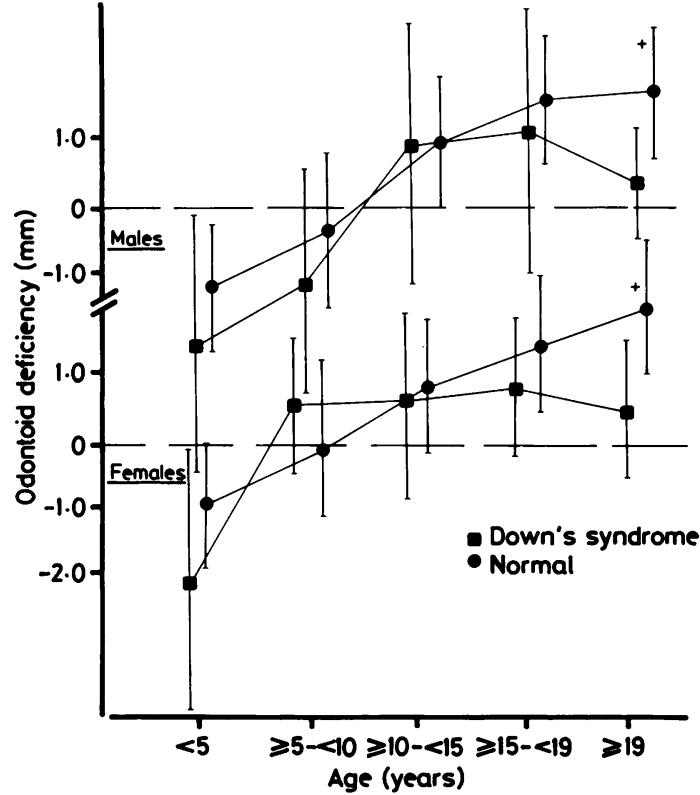

Fig 3 Odontoid deficiency at different ages in people with Down's syndrome and in normal controls. $+=$ Significant difference, $p<0 \cdot 05$.

atlantoaxial instability together with a hypoplastic peg and os odontoideum. There was poor correlation between odontoid hypoplasia and significant odontoid deficiency; 29 people had odontoid hypoplasia but only seven had odontoid deficiency and six others had odontoid deficiency alone. Four patients had accessory ossicles, one of whom had odontoid hypoplasia.

No patients with atlantoaxial instability had signs or symptoms of spinal cord compression.

\section{Discussion}

In people under the age of 15 we found an incidence of atlantoaxial instability of $10 \%$, taking the upper limit of normal as $4 \mathrm{~mm} .^{22}$ This was low compared with other studies, which indicated frequencies of $9 \cdot 5-27 \%$ with $4-5 \mathrm{~mm}$ as the upper limit of normal. ${ }^{5-7}$ For those people over the age of 15 , we found an incidence of $2 \%$ with atlantoaxial instability using the same criteria. This figure is again low in comparison with the main study in adults, showing atlantoaxial instability in $10 \%$ of adults with a gap over $5 \mathrm{~mm} .{ }^{25}$ We feel the major reason for finding a low incidence of atlantoaxial instability was because we did not encourage hyperflexion of the neck, which is used in some studies to maximise the atlantoaxial gap. We considered this could be 
potentially dangerous and instead we simply asked the patients to flex their necks as much as was comfortable. Any difference between studies of the object-tube distance in taking the radiographs would be insignificant. Our patients were predominantly living in the community and included a wide range of all types of people with Down's syndrome. Many of the American series studied only institutionalised patients who could be expected to be in general more retarded with a possibily higher incidence of atlantoaxial instability.

In our study an extension film was found to be unnecessary in screening the neck in Down's syndrome, one film in flexion indicating the maximal atlantoaxial gap and another in neutral allowed accurate visualisation of the odontoid peg. Recently Pueschel, however, reported a series in which up to $25 \%$ of people with atlantoaxial instability would have been missed if an extension film was excluded. ${ }^{26}$

Our study concerned a large group of people with Down's syndrome of all ages and indicated that the mean atlantoaxial gap is wider in young people compared with adults and that a greater proportion of young people have significant atlantoaxial subluxation. Laxity of the transverse ligament of the atlas predisposes to atlantoaxial instability, and this correlates with the degree of ligamentous laxity present in other joints in children with Down's syndrome. ${ }^{6}$ Children also suffer from upper respiratory infections and trauma, both of which may cause atlantoaxial instability. ${ }^{14} 1627$

There could be a greater degree of ligamentous laxity in adults because of degeneration of the transverse ligament, which like other aging processes, may occur faster in Down's syndrome. Different pathological processes may therefore be responsible for atlantoaxial instability in children and adults and occur in different people. In the only published longitudinal study of atlantoaxial instability in Down's syndrome radiographs were taken in 32 patients, 13 years apart. ${ }^{10}$ One person had atlantoaxial instability initially but this disappeared, seven others originally had normal necks but later developed atlantoaxial instability.

We found that the odontoid peg was generally smaller in children and adults with Down's syndrome compared with normals. This is probably mainly because of the smaller stature in Down's syndrome, together with delayed growth of the peg in children due to their skeletal immaturity. The odontoid peg does appear to be proportionally smaller in Down's syndrome as the odontoid deficiency is greater in Down's syndrome, but this was only significant in the adult group. Nevertheless, there is poor correlation between odontoid hypo- plasia and odontoid deficiency and it is unclear which measurement of the odontoid peg is of most clinical importance. We prefer the measurement of odontoid hypoplasia that is used in other seriesthat is, odontoid height; we found that $17 \%$ of children had odontoid hypoplasia, that is two standard deviations below the mean for an age matched normal population. This compared with $6 \%$ in another series, ${ }^{6}$ although the criteria were not mentioned. A total of $20 \%$ of adults in our series also had odontoid hypoplasia, two standard deviations below the mean.

We did not find any correlation between odontoid hypoplasia and atlantoaxial instability. Only one child had these conditions together $(1.5 \%)$ and one adult had both conditions with an accessory os odontoideum $(1 \%)$. Previous reports suggest that these people are at particular risk of neurological damage resulting from cord compression. ${ }^{8-17}$ Cord damage may occur in these cases even with mild odontoid hypoplasia because the lax transverse ligament overrides the odontoid peg and is held back only by the apical and alar ligaments connecting odontoid and occiput. Perhaps even more importantly, when an os odontoideum is present, the detached upper part of the odontoid can move forward and sometimes remain permanently dislocated. ${ }^{11}$ Pueschel et al feel that an atlantoaxial gap of $7 \mathrm{~mm}$ is sufficient to cause cord compression. ${ }^{27}$

Symptoms resulting from abnormalities of the atlantoaxial region in Down's syndrome appear to be rare. Out of 161 people in our series, seven children and two adults had atlantoaxial instability, but none had symptoms. Semine et al found 10 children with atlantoaxial instability, only one of whom had symptoms. ${ }^{6}$ Pueschel et al found seven out of 40 children with atlantoaxial instability had symptoms $(18 \%)$, indicating an overall prevalence of symptoms in $2 \%$ of Down's syndrome children. ${ }^{27}$ From a review of the world literature, together with personal reports, Pueschel et al collected 42 cases of symptomatic atlantoaxial instability. Two of these became symptomatic in their mid forties and the rest were much younger, with mean age incidence of 10.5 years. Children would be expected to suffer more symptoms because of the higher incidence of atlantoaxial instability and because the spinal cord is more easily compressed, being enclosed in a relatively smaller spinal canal. It is possible that the under developed odontoid peg in childhood also predisposes to overriding of the transverse ligament in the way described. Pueschel et al also noted that females have a greater incidence of symptoms of atlantoaxial instability by a factor of $2 \cdot 3: 1$. $^{27}$ We cannot account for this, as our study showed no significant differences between the sexes in 
terms of the incidence of atlantoaxial instability, odontoid hypoplasia, or accessory ossicles.

There is understandable concern that flexion of the neck during certain sporting activities may damage the spinal cord in people with atlantoaxial instability. This has led to recommendations that people with Down's syndrome should have radiographs taken of the neck before participating in such sports as diving, trampolining, pentathlon events, and violent contact sports such as boxing. ${ }^{12}$ Radiographs should also be taken before intubation for anaesthesia as excessive manipulation of the neck may be involved and this has resulted in cord damage in some people with atlantoaxial instability. ${ }^{28}$ Most symptoms from atlantoaxial instability do not result from specific injuries and the DHSS has also recommended clinical surveillance to check on the development of signs or symptoms of cord compression in all people with Down's syndrome. ${ }^{2}$ Surgery is indicated for those with cord damage, usually concerning posterior fusion of the atlas and axis vertebrae.

While existing recommendations are sufficient for adults, there remains some difficulties in managing atlantoaxial instability in children. Some feel that radiographic screening should take place for all children with Down's syndrome as the school curriculum contains many activities that could damage the neck, for example, forward rolls in gymnastics and general rough and tumble activities. In the absence of radiographic screening, we know of some school authorities that restrict the activities of all children with Down's syndrome to prevent injuries occurring. Radiographic screening for atlantoaxial instability in children attending school, in addition to regular clinical checks, has therefore become a contentious issue. Those in favour of screening point to the importance of prevention of cord damage before it occurs, ${ }^{29} 30$ especially when these individuals may not be able to indicate their symptoms and surgery is not always successful. ${ }^{9}$ Those against radiographic screening point to the rarity of neurological damage from atlantoaxial instability. They feel this does not justify the use of an insensitive screening test which may cause undue parental anxiety and lead to the unnecessary restriction of activity in some people.

Following our study, our current practice in Southern Derbyshire is to screen all children with Down's syndrome for atlantoaxial instability with radiographs of the cervical spine in the flexion and neutral position, at school entry around the age of 5 . About $83 \%$ of the children are unaffected and allowed normal activity. The remaining $17 \%$ with atlantoaxial instability are restricted from diving, trampolining, gymnastics including forward rolls, and contact sport such as rugby and boxing. They are encouraged to take part in other sports such as running, swimming, and slow horse riding; radiographs are repeated yearly. All children are checked clinically for signs of cord compression on an annual basis. We plan to repeat the radiography on all children at the age of 10 . Particular care is taken over those with both atlantoaxial instability and odontoid hypoplasia or accessory ossicles or with atlantoaxial instability alone exceeding $7 \mathrm{~mm}(1-2 \%$ of the total). We feel this is a reasonable approach to preventing serious neurological damage occurring in these children. Adults should be checked clinically on an annual basis and screened radiologically before taking part in certain sports or before anaesthesia. We will be evaluating this programme over the coming years, in particular to determine why some people with atlantoaxial instability go on to develop symptoms and whether restricting activity does in fact help prevent them.

We are grateful to the staff of the radiology departments of the Derbyshire Children's Hospital and Derbyshire Royal Infirmary and to physiotherapists working in community handicap teams who arranged $x$ ray screening for adults with Down's syndrome. We are grateful to Dr C Murray-Leslie and Dr AP Abdulla for allowing us to study adult patients under their care. Thanks also to Mrs Karen Purnell for typing the manuscript.

\section{References}

${ }^{1}$ Committee on Sports Medicine. Atlanto-axial instability in Down's syndrome. Pediatrics 1984;74:152-3.

2 Department of Health and Social Security. Atlanto-axial instability in people with Down's syndrome. London: DHSS, 1986.

${ }^{3}$ Royal Society for Mentally Handicapped Children and Adults. Give them a sporting chance. London: Mencap, 1986. (Information sheet.)

4 Tishler JM, Martel W. Dislocation of the atlas in mongolism. Preliminary report. Radiology 1965;84:904-6.

5 Martel W, Tishler JM. Observation of the spine in mongoloidism. American Journal of Roentgenology, Radium Therapy and Nuclear Medicine 1966;94:630-8.

- Semine AA, Ertel AN, Goldberg MJ, Bull MJ. Cervical spine instability in children with Down's syndrome. J Bone Joint Surg [Am] 1978;60:649-52.

7 Pueschel SM, Scola FH, Perry CD, Pezzullo JC. Atlanto-axial instability in children with Down's syndrome. Pediatr Radiol 1981;10:129-32.

${ }^{8}$ Dawson EG, Smith L. Atlanto-axial subluxation in children due to vertebral anomalies. J Bone Joint Surg [Am] 1979;61:582-7.

${ }^{9}$ Nordt JC, Stauffer ES. Sequelae of atlanto-axial stabilization in two patients with Down's syndrome. Spine 1981;6:437-40.

10 Burke SW, French Capt HG, Roberts JM, et al. Chronic atlanto-axial instability in Down's syndrome. J Bone Joint Surg [Am] 1985;67:1356-60.

1 Sherk HH, Nicholson JT, Rotatory atlanto-axial dislocation associated with ossiculum terminale and mongolism. J Bone Joint Surg [Am] 1969;51:957-64.

12 Hungerford GD, Akkaraju V, Rawe SE, Young GF. Atlantooccipital and atlanto-axial dislocations with spinal cord compression in Down's syndrome. Br J Radiol 1981;54:758-61.

${ }^{13}$ Hreidarsson S, Magram G, Singer H. Symptomatic atlanto-axial dislocation in Down's syndrome. Pediatrics 1982;69:568-71.

${ }^{14}$ Finerman GAM, Sakai D, Weingarten S. Atlanto-axial disloca- 
tion with spinal cord compression in a mongoloid child. $J$ Bone Joint Surg [Am] 1976;58:408-9.

15 Shield LK, Dickens DRV, Jensen F. Atlanto-axial dislocation with spinal cord compression in Down's syndrome. Aust Pediatr $J$ 1981;17:114-6.

16 Whaley WJ, Gray WD. Atlanto-axial dislocation and Down's syndrome. Can Med Assoc J 1980;123:35-7.

${ }^{17}$ Martel W, Uyham R, Stimson CW. Subluxation of the atlas causing spinal cord compression in the case of Down's syndrome with a manifestation of an occipital vertebra. Radiology 1969;93: 838-40.

18 Rosenbaum DM, Blumhagen TD, King HA. Atlanto-occipital instability in Down's syndrome. AJR 1986;146:1269-72.

19 El Khoury GY, Clark CR, Dretz FR, et al. Posterior atlantooccipital subluxation in Down's syndrome. Radiology 1986;159: 507-9.

${ }^{20}$ Elliott S. The odontoid process in children: is it hypoplastic? Clin Radiol 1988;39:391-3.

${ }^{21}$ Swallow RA, Naylor E, Roebuck EJ, Whitley AS. The vertebral column. Clark's positioning in radiography. 11th ed. London: Heinemann, 1986:156.

22 Locke GR, Gardner JI, Van Epps EF. Atlas-dens interval in children. AJR 1966;97:135-40.

23 Von Torklus D, Gehle W. The upper cervical spine. London: Butterworths, 1972.
24 McManners T. Odontoid hypoplasia. Br J Radiol 1983;56: 907-10.

${ }^{25}$ Alvarez N, Rubin L. Atlanto-axial instability in adults with Down's syndrome. Appl Res Ment Retard 1986;7:67-78.

${ }^{26}$ Pueschel SM, Scola FH. Atlanto-axial instability in individuals in Down's syndrome: epidemiologic, radiographic and clinical studies. Pediatrics 1987;80:555-60.

${ }^{27}$ Pueschel SM, Herndon JH, Gelch MM, Senft KE, Scola FH, Goldberg MJ. Symptomatic atlanto-axial subluxation in persons with Down's syndrome. J Pediatr Orthop 1984;4:682-8.

${ }^{28}$ Moore RA, McNicholas KW, Warren SP. Atlanto-axial subluxation with symptomatic spinal cord compression in a child with Down's syndrome. Anesth Analg 1987;66:89-90.

29 Pueschel SM, Findley TW, Furia J, Gallagher PL, Scola-FH, Pezzello J. Atlanto-axial instability in Down's syndrome; roentgenographic neurologic and somatosensory evoked potential studies. J Pediatr 1987;110:515-21.

${ }^{30}$ Collacott RA. Atlanto-axial instability in Down's syndrome. [Editorial.] Br Med J 1987;294:988-9.

Correspondence to Dr S Elliott, Department of Radiology, Derbyshire Royal Infirmary, London Road, Derby DE1 2QT.

Accepted 6 May 1988 